\title{
Effects of the Support Surface Condition on Muscle Activity of Trunk Muscles during Balance Exercises in Patients with Stroke
}

\author{
Kyoung-Sim Jung', Yong-Su Kim², Tae-Sung $\ln ^{1}$ \\ 'Department of Physical Therapy, The Graduated School, Sahmyook University, Seoul; ${ }^{2}$ Department of Physical Therapy, Health Cluster, Shinsung \\ University, Dangjin, Korea
}

Purpose: The purpose of this study was to examine the muscle activity of the trunk muscles during balance exercises on a stable and unstable surface in patients with stroke.

Methods: Thirteen subjects (8 males, 5 females) with stroke were enrolled in the study. Muscle activity was recorded using surface EMG electrodes from the affected side of the erector spinae, external oblique, and internal oblique muscles.

The exercise was performed under three conditions. For the first condition for balance exercise, subjects were instructed to sit on an exercise mat with legs extended. The second condition was to sit with legs extended, with a balance pad under their buttocks. The third condition was to sit with legs extended, have a balance pad under the buttocks and a balance cushion under the lower legs.

Results: This study showed significant differences in EMG activities during both arm lifting exercise and weight shifting exercise between conditions. This study showed that the EMG activities of the erector spinae, external oblique, and internal oblique muscles were significantly higher when the trunk exercise was performed using the balance pad with balance ball than when using the stable surface. Conclusion: In conclusion, performing balance exercises using an unstable surface is a useful method for facilitating trunk-muscle strength and hence trunk stability.

Keywords: Eletromyography, Stroke, Torso

\section{서 론}

체간 조절은 기저면 내에서 무게중심을 유지하기 위해 체간의 선택적 인 움직임을 수행하는 능력으로, ${ }^{1}$ 뇌졸중 환자는 체간 근력이 떨어지 게 되며, 비대칭적인 골반 정렬로 인해 체간의 자세 조절뿐 아니라 ${ }^{2}$ 체 간 근력 및 앉은 자세의 균형 능력이 떨어지게 된다. ${ }^{3}$ 앉은 자세의 균 형 능력은 기능적 회복의 예측인자로, 선 자세에 비해 무게중심이 낮 아짐에 따라 균형 유지를 위한 체간 근육의 역할이 중요해진다. ${ }^{4}$

뇌졸중 환자의 기능 향상을 위해서는 실제 생활에서의 과제를 반 복적으로 훈련하는 것이 효과적이며, 뇌졸중 환자를 위한 중재 프로 그램은 적절한 근거에 기반을 두고 시간적, 경제적 비용 문제를 고려 해야 한다. ${ }^{5}$ 앉은 자세에서의 균형을 개선하기 위한 훈련 방법으로 골 반 경사 운동이나 팔. 다리를 이용한 체간 안정화 운동, 체중 이동 운 동 등이 있다. 앉은 자세에서 팔 들기는 운동을 하는 동안 발생한 자 세동요에 대항하기 위해 체간 근육이 수축하게 되고, ${ }^{7}$ 체중 이동 운

Received Jul 23, 2015 Revised Aug 13, 2015

Accepted Aug 21, 2015

Corresponding author Tae-Sung In

E-mail in8386@naver.com
동 중에는 무게중심의 변화에 대응하여 체간의 정렬을 조정하는 능 력이 요구된다. ${ }^{8}$

불안정한 면에서의 운동은 자세 동요를 증가시켜 자세 유지를 위 한 체간 근육의 활성을 더욱 촉진시킨다.9 van Nes 등10은 만성 뇌졸중 환자를 대상으로 지지면에 따른 앉은 자세에서의 동요거리를 측정 한 결과, 대조군에 비해 불안정한 지지면에서 자세 동요거리가 유의 하게 큰 것으로 나타났으며, 따라서 불안정한 지지면을 사용하는 것 은 균형 훈련에 중요한 요소가 될 수 있다고 하였다.

정상 성인을 대상으로 지지면에 따라 네발기기와 교각자세에서 체 간 근육의 활성도를 비교한 연구에서는 지지면이 불안정할때 복근 과 척추 기립근의 활성도가 증가된다고 하였다.11,12 Karthikbabu 등은 뇌졸중 환자를 대상으로 불안정한 면 위에서 앉은 자세에서의 균형 훈련을 실시한 결과 자세조절 및 균형능력이 개선되었으나, 이러한 개선 효과가 체간 근육의 활성도 증가에 기인한 것인지 확인되지 못 하였다. 뇌졸중 환자를 대상으로 교각 운동시 무릎 각도에 따른 체간 
근육의 활성도를 비교한 연구에서는 양쪽 무릎각도를 달리 했을 때 와, ${ }^{13}$ 다리가 체간으로부터 멀어질수록 환측 체간 근육의 활성도가 증가된다고 하였으며, ${ }^{14}$ 지지면에 따른 차이는 비교하지 않았다.

뇌졸중 환자를 대상으로 반복적인 체간 훈련이 체간 근육의 활성 도에 효과가 있다는 연구가 있었지만, ${ }^{15}$ 지지면이 체간 근육의 활성도 에 영향을 미치는지에 대한 연구는 매우 부족한 실정이다. 또한 지지 면에 따른 체간 근육의 활성도를 비교한 연구들은 대부분 정상인을 대상으로 교각운동이나 네발기기 자세 등 대칭적인 자세에서만 측정 하였다. ${ }^{16}$ 따라서 본 연구에서는 뇌졸중 환자를 대상으로 앉은 자세 에서 체중 이동을 포함한 균형 운동시 지지면이 체간 근육의 활성도 에 미치는 영향을 알아보고자 한다.

\section{연구방법}

\section{1. 연구대상}

본 연구는 경기도 구리시에 소재한 재활 병원에 입원중인 뇌졸중 환 자를 대상으로 실시하였다. 선정 기준에 적합한 환자 중 실험에 대한 설명을 듣고 동의한 남자 8 명, 여자 5 명 총 13 명을 대상으로 실시하였 다. 선정기준은 30 초 이상 독립적으로 앉은 자세를 유지할 수 있는자, 편측 무시(neglect)가 없는 자, 양측성 뇌졸중, 또는 이전에 반대쪽의 대뇌 반구에 발병 경험이 없는 자, 말초성 신경염을 가지고 있지 않은 자, 급성 근골격계 문제가 없는 자, 의사소통이 가능하며 피 실험자의 지시를 이해하고 수행할 수 있는 자를 실험대상으로 하였다. ${ }^{9}$ 연구 대 상자의 평균 나이는 평균 $56.6 \pm 5.7$ 세, 유병기간은 평균 $22.7 \pm 6.8$ 개월 이었으며 손상부위는 왼쪽이 8 명 오른쪽이 5 명이었다(Table 1).

\section{2. 실험방법}

\section{1) 실험절차}

선정기준에 적합한 뇌졸중 환자 13 명을 대상으로 양팔 들기와 체중 이동 운동시 지지면에 따른 환측 체간 근육의 활성도를 측정하였다.

양팔 들기와 체중 이동 운동은 무릎을 펴고 앉은 자세에서 실시하

Table 1. General characteristics of subject

$(N=11)$

\begin{tabular}{lc}
\hline & Subjects \\
\hline Gender (male/female) & $(8 / 5)$ \\
Age (year) & $56.6 \pm 5.7$ \\
Body weight (kg) & $65.9 \pm 7.3$ \\
Height (cm) & $165.5 \pm 7.3$ \\
Duration of stroke (month) & $22.7 \pm 6.8$ \\
Paretic side (right/left) & $5 / 8$ \\
Lesion type (hemorrhage/ischemia) & $4 / 9$ \\
Brunnstrom stage (3/4) & $10 / 3$ \\
\hline
\end{tabular}

Values are expressed as mean \pm standard deviation (SD).
였으며, 불안정한 정도에 따라 세 가지 조건에서 무작위 순서로 측정 하였다.

첫 번째는, 안정한 면 위에 무릎을 펴고 앉은 상태에서 운동을 실 시하였다.

두 번째는, 둔부 아래에 발란스 패드(Balance pad, Airex ${ }^{\circledR}$, Germany) 를 대고 무릎을 펴고 앉은 상태에서 운동을 실시하였다.

마지막으로 세 번째는, 둔부 아래에 발란스 패드를 대고 하퇴와 발 아래에는 발란스 볼(balance ball, Togu, Germany)을 대고 무릎을 펴 고 앉은 상태에서 운동을 실시하였다(Figure 1,2).

보다 정확하게 수행하기 위해 대상자들은 평가를 하기 전, 안정된 면에 앉은 상태에서 체중 이동 및 양팔 들기 동작에 대한 연습을 충 분히 하였다. 양팔 들기의 경우, 안정된 면에서 최대한 팔을 올릴 수

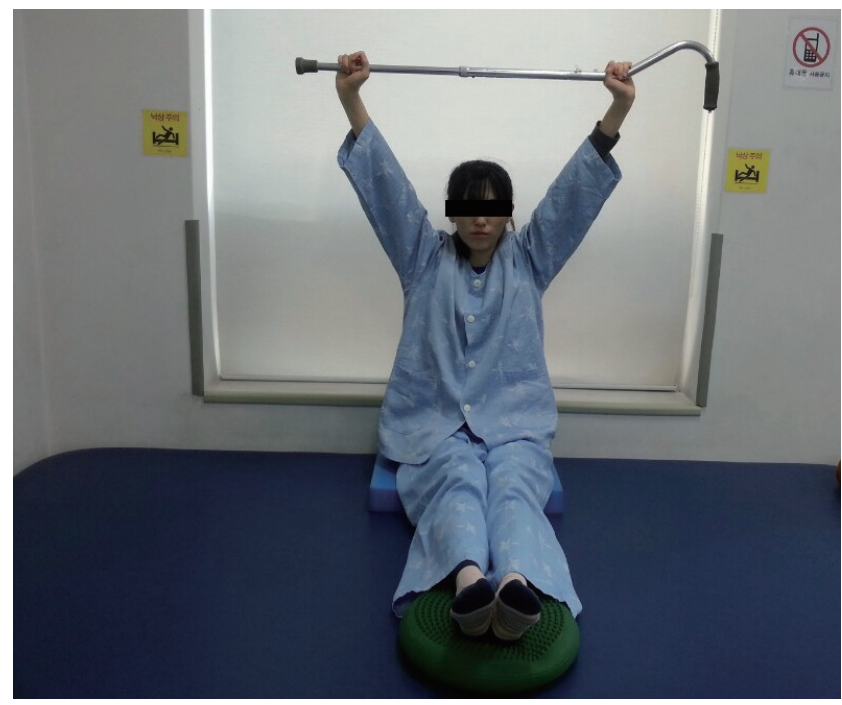

Figure 1. Arm lifting exercise.

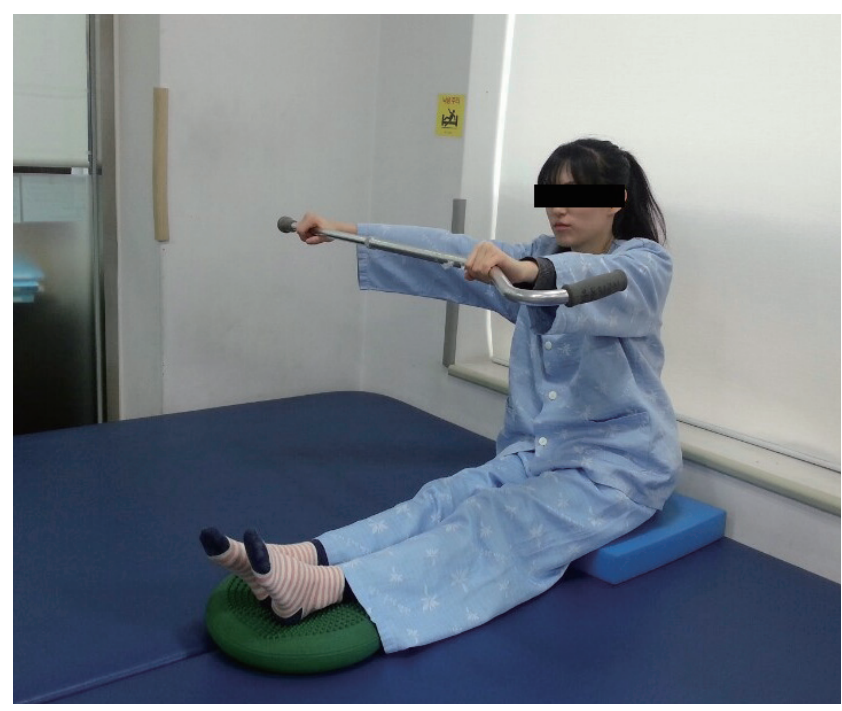

Figure 2. Weight shifting exercise. 
있는 높이를 측정하여 눈금이 그려진 거울에 마커를 부착하였다. 측 정은 양손으로 지팡이를 잡고, 어깨관절이 90 도가 되도록 팔을 올린 상태에서 시작하여 최대한 팔을 들어올리게 하였으며, 양팔을 들어 지팡이가 기준점에 도달하고 5 초간 자세를 유지하게 하였다.

체중 이동의 경우 안정된 면 위에 무릎을 펴고 앉은 자세에서 환측 으로 최대 이동 가능한 거리를 측정하여 바(bar)를 설치하였다. 체중 지지측 체간의 길이가 늘어나고 반대측 체간의 길이가 짧아지도록 체중이동을 하여 환측 견봉(arcromion)이 기준점까지 도달하고 5 초 간 자세를 유지하도록 하였다. 자료 분석은 처음 1 초와 마지막 1 초를 제외한 3 초 동안 측정된 근 활성도를 사용하였다. 운동 시 피로를 고 려하여 각 운동 후 1 분간의 휴식을 취하게 하였으며, 각 운동은 3 번 측정하여 평균값을 구하였다.

\section{2) 측정도구와 자료수집과정}

세 가지 조건에서 균형 운동을 하는 동안 근 활성도를 측정하기 위해 표면 근전도(Telemyo 2400 G2 Telemetry EMG system, Noraxon, U.S.A. 2007)를 사용하였다. 표본 추출률(sampling rate)은 $1,000 \mathrm{~Hz}$ 으로 설정 하였고, 주파수 대역폭은 10-500 Hz로 하였다. 양쪽 체간의 척추 기립 근(Erector Spinae)과 외복사근(External Oblique), 내복사근(Internal Oblique)에 전극을 부착하였으며, 전극을 부착하기 전 피부 저항을 최소화하기 위해 털을 제거하고 알코올로 부착부위를 깨끗이 닦은 후 전극을 부착하였다. 척추 기립근은 요추 3 번에서 외측으로 $2 \mathrm{~cm}$ 떨 어진 지점에 부착하였으며, 외복사근은 배꼽에서 외측으로 $15 \mathrm{~cm}$ 떨 어진 지점에 부착하였다. 내복사근은 전상장골극에서 하. 내방으로 $2 \mathrm{~cm}$ 지점에 부착하였다. ${ }^{17}$

이 연구에서 측정한 근육의 근전도 신호는 전파정류(full wave rectification)로 처리 후 root mean square (RMS) 값을 취하였다. 각 근육 의 활동전위를 표준화하기 위해 수의적 최대 등척성 근수축 값으로 나누어 백분율로 환산한 값인 \%MVIC 값을 사용하여 체중 이동시 근전도 신호를 정규화(normalization)하였다. 각 근육의 최대 등척성

Table 2. Comparison of activation of the trunk muscles according to the support surface conditions during arm lifting exercises (\%MVIC)

\begin{tabular}{lcccc}
\hline Parameter & Stable & Balance pad & $\begin{array}{c}\text { Balancepad+ } \\
\text { balance ball }\end{array}$ & $p$ \\
\hline ES & $24.28 \pm 18.66^{\ddagger}$ & $26.97 \pm 18.89^{+}$ & $32.94 \pm 18.56^{*+}$ & 0.01 \\
EO & $40.97 \pm 17.37^{\ddagger}$ & $42.89 \pm 18.83^{+}$ & $52.94 \pm 24.49^{*+}$ & 0.03 \\
IO & $50.63 \pm 17.60^{+}$ & $52.76 \pm 18.20^{+}$ & $58.77 \pm 17.17^{*+}$ & 0.01 \\
\hline
\end{tabular}

Values are expressed as mean \pm standard deviation (SD). ES, Erector spinae; EO, External oblique; IO, Internal oblique.

*indicates a significant differences compared with stable surface condition $(p<0.05)$; 'indicates a significant differences compared with balance pad condition $(p<0.05)$; *indicates a significant differences compared with balance pad + balance ball condition $(p<0.05)$.
수축값은 3 번 측정하여 평균값을 구하였다.

3) 분석방법

본 연구에서는 SPSS ver.18.0을 이용하여 자료를 분석하였다. 세 가지 조건에서 체간 근육의 활성도 차이는 일원 반복측정 분산분석(oneway repeated ANOVA)을 사용하였고, 사후 검증은 최소유의차검증 (least significant difference, LSD)을 이용하여 분석하였다. 통계학적 유 의수준은 0.05 이하로 하였다.

\section{결 과}

\section{1. 양팔 들기 운동시 지지면에 따른 체간 근활성도의 변화}

앉은 자세에서 양팔 들기 운동시 지지면에 따라 3 가지 조건에서 환측 체간 근육의 활성도를 비교한 결과, 지지면에 따라 근 활성도에 유의 한 차이가 있는 것으로 나타났다. 환측 척추기립근, 외복사근과 내복 사근 모두 발란스 패드와 발란스 볼을 적용하였을 때 가장 높은 근 활성도를 나타내었으며(각각 $32.94 \pm 18.56 \% \mathrm{MVIC}, 52.94 \pm 24.49$ $\% \mathrm{MVIC}, 58.77 \pm 17.17 \% \mathrm{MVIC})(\mathrm{p}<0.05)$, 안정된 면과 둔부 아래 발란 스 패드만 적용하였을 때는 두 방법간 유의한 차이가 나타나지 않았 다(Table 2).

\section{2. 체중 이동 운동시 지지면에 따른 체간 근활성도의 변화}

체중 이동 운동시 환측 외복사근과 내복사근은 지지면에 따른 세 가 지 조건에서 근 활성도에 모두 유의한 차이가 있었다. 환측 척추 기립 근의 경우에는 발란스 패드와 발란스 볼을 모두 적용하였을 때가 $40.97 \pm 16.99 \% \mathrm{MVIC}$ 로 안정된 면과 발란스 패드만 적용하였을 때(각 각 $37.64 \pm 15.70 \% \mathrm{MVIC}, 38.81 \pm 16.06 \% \mathrm{MVIC}$ )보다 유의하게 높은 근 활성도를 나타내었으며 $(\mathrm{p}<0.05)$, 안정된 면과 둔부 아래 발란스 패드 만 적용하였을 때는 두 방법간 근 활성도에 유의한 차이가 나타나지 않았다(Table 3).

Table 3. Comparison of activation of the trunk muscles according to the support surface conditions during weight shifting exercises (\%MVIC)

\begin{tabular}{lcccc}
\hline Parameter & Stable & Balance pad & $\begin{array}{c}\text { Balancepad+ } \\
\text { balance ball }\end{array}$ & $p$ \\
\hline ES & $37.64 \pm 15.70^{+}$ & $38.81 \pm 16.06^{*}$ & $40.97 \pm 16.99^{*+}$ & 0.02 \\
EO & $36.69 \pm 17.00^{+\neq}$ & $39.36 \pm 15.70^{* \neq}$ & $41.93 \pm 14.86^{*+}$ & 0.01 \\
IO & $49.79 \pm 21.38^{+\neq}$ & $53.53 \pm 20.57^{* \neq}$ & $57.97 \pm 19.20^{*+}$ & 0.01 \\
\hline
\end{tabular}

Values are expressed as mean \pm standard deviation (SD).

ES, Erector spinae; EO, External oblique; IO, Internal oblique.

* indicates a significant differences compared with stable surface condition $(p<0.05)$; indicates a significant differences compared with balance pad condition $(p<0.05)$; ; indicates a significant differences compared with balance pad + balance ball condition $(p<0.05)$. 


\section{고 찰}

본 연구에서는 뇌졸중 환자를 대상으로 앉은 자세에서의 균형 운동 시 지지면이 체간 근육의 활성에 미치는 영향에 대해 알아보기 위해, 불안정한 정도에 따라 세 가지 조건하에서 체간 근육의 활성도를 비 교하였다. 그 결과 앉은 자세에서 양팔 들기 운동시 발란스 패드와 발 란스 볼을 모두 적용하였을 때 다른 두 가지 조건에 비해 척추 기립근 과, 외복사근 및 내복사근의 근 활성도가 유의하게 높은 것으로 나타 났다.

앉은 자세에서 팔을 들때 무게 중심이 전방으로 이동됨에 따라 자 세 안정성을 유지하기 위해 체간의 모멘트가 후방으로 작용하게 되 고, ${ }^{18}$ 이러한 무게중심의 이동과 반발력(reaction force)에 기인하여 자 세동요가 발생하게 된다. ${ }^{19}$ 불안정한 면에서 체간의 안정성을 유지하 기 위해서는 지면의 흔들림에 따른 자세 변화를 인식하고 무게중심 을 기저면 안에서 유지하기 위해 신경계의 조절을 통한 근육들의 적 절한 협응 작용이 필요하다. ${ }^{20,21}$ 본 연구에서 발란스 패드와 발란스 볼을 모두 적용하였을 때 지면의 흔들림에 따라 이에 대한 반발력이 증가함으로써 체간 근육의 활동을 더욱 촉진시킨 것으로 생각된다. 지지면이 불안정한 경우에는 신체가 균형을 유지하기 위해 신체 분 절을 지나는 근육들의 공동 수축이 증가하고, 근방추를 민감하게 만 들어 줌으로써 관절의 안정성에 영향을 미치게 된다. ${ }^{22}$ 그러나 본 연 구에서 양팔 들기 운동시 발란스 패드만 적용하였을 때는 안정된 면 과 근 활성도에서 유의한 차이가 나타나지 않았다. 이러한 이유는 본 연구에서 30 초 이상 독립적으로 앉아 있을 수 있는 환자를 대상으로 하였기 때문에 발란스 패드만 적용하였을 때는 불안정한 강도가 다 소 약했을 것이라고 판단된다.

또한 본 연구에서는 지지면에 따른 체중 이동 운동시 체간 근육의 근 활성도를 비교하였다. 그 결과 환측 외복사근과 내복사근이 지지 면에 따른 세 가지 조건에서 근 활성도에 모두 유의한차이가 있는 것 으로 나타났다. Marshall과 Murphy ${ }^{10}$ 는 불안정한 면 위에서 무게중심 이 중심선에서 멀어질수록 체간에 대한 자세동요 및 과제수행과 관 련된 근육의 활동이 증가된다고 하였다. 본 연구에서는 근 활성도를 측정하기 전 최대 체중이동 거리를 미리 확인하였으며, 목표지점에 도달했을 때 5 초간 유지하게 하여 자세동요가 증가된 상태에서 체간 근육의 활동을 기록하였다. 외복사근과 내복사근의 근 활성도가 세 가지 조건에서 모두 유의한 차이를 보인 것은 불안정한 강도가 높을 수록 체중 이동시 자세동요가 증가하기 때문에 균형을 잡기 위해 더 욱 많은 근수축을 유발한 것으로 생각된다.

그러나 척추 기립근의 경우 안정된 면과 발란스 패드만 적용하였 을 때는 유의한 차이가 없는 것으로 나타났다. 이것은 척추기립근이 중축성(axial)의 체간 근육으로 편측 우세적 경향을 보이는 외복사
근, 내복사근과 같은 외측 척추 기립근에 비해 체중 이동시 지지면의 영향을 비교적 적게 받은 것으로 생각되며, ${ }^{23,24}$ 발란스 패드와 발란스 볼을 모두 적용하였을 때 유의하게 근 활성도가 증가한 것은 둔부쪽 으로 무게중심이 이동되면서 척추 기립근의 역할이 중요해진 것으로 생각된다.

자세 조절은 보행이나 움직임 수행 시 자세 유지를 위한 기본적인 요소로, 독립적인 일상생활을 위해 반드시 필요하다. ${ }^{25}$ 본 연구에서 는 뇌졸중 환자를 대상으로 앉은 자세에서의 균형 운동시 지지면에 따른 체간 근육의 활성도를 비교한 결과, 불안정한 면에서 운동시 안 정된 면보다 근 활성도가 증가하는 것으로 나타났으며, 자세동요가 증가하는 환경일수록 균형을 유지하기 위한 근육의 활동이 증가하 는 것을 알 수 있었다. 그러나 연구의 대상자수가 적어 일반화하기 어 려우며, 지면의 불안정한 정도에 따른 자세동요의 차이를 비교하지 않았다. 또한 본 연구에서는 불안정한 면에서의 반복적인 균형 훈련 이 뇌졸중 환자의 손상된 체간 근육의 활성도에 어떠한 영향을 미치 는지 확인하지 못했다. 따라서 앞으로의 연구에서는 뇌졸중 환자를 대상으로 불안정한 면에서의 반복적인 균형 훈련이 체간 근육의 활 성도 및 자세조절에 미치는 효과를 알아보는 연구가 필요하겠다. 본 연구의 결과는 자세조절이 손상된 뇌졸중 환자들의 불안정한 면에 서의 균형 훈련의 효과에 대한 근거를 제시해 줄 수 있을 것으로 기대 된다.

\section{REFERENCES}

1. Verheyden G, Nieuwboer A, Mertin J et al. The Trunk Impairment Scale: a new tool to measure motor impairment of the trunk after stroke. Clin Rehabil. 2004;18(3):326-34.

2. Seo HJ, Kim JH, Choi MJ et al. The effects of gluteal taping on pelvic alignment, trunk stability, and balance during sitting in children with unilateral cerebral palsy. J Kor Phys Ther. 2014;26(5):308-14.

3. Verheyden G, Nieuwboer A, De Wit L et al. Time course of trunk, arm, leg, and functional recovery after ischemic stroke. Neurorehabil Neural Repair. 2008;22(2):173-9.

4. van de Port IG, Kwakkel G, Schepers VP et al. Predicting mobility outcome one year after stroke: A prospective cohort study. J Rehabil Med. 2006;38(4):218-23.

5. Deutsch JE, Merians AS, Adamovich S et al. Development and application of virtual reality technology to improve hand use and gait of individuals post-stroke. Restorative neurology and neuroscience. 2004; 22(3):371-86

6. Yeom JN, Lim CG. Change of statics and dynamic foot pressure after trunk stabilization exercises in children with spastic diplegic cerebral palsy. J Kor Soc Phys Ther. 2014;26(4):274-9.

7. Dickstein R, Shefi S, Marcovitz E et al. Anticipatory postural adjustment in selected trunk muscles in post stroke hemiparetic patients. Arch Phys Med Rehabil. 2004;85(2):261-7.

8. Lanzetta D, Cattaneo D, Pellegatta D et al. Trunk control in unstable sit- 
ting posture during functional activities in healthy subjects and patients with multiple sclerosis. Arch Phys Med Rehabil. 2004;85(2):279-83.

9. Karthikbabu S, Nayak A, Vijayakumar K et al. Comparison of physio ball and plinth trunk exercises regimens on trunk control and functional balance in patients with acute stroke: a pilot randomized controlled trial. Clin Rehabil. 2011;25(8):709-19.

10. van Nes IJ, Nienhuis B, Latou H et al. Posturographic assessment of sitting balance recovery in the subacute phase of stroke. Gait Posture. 2008;28(3):507-12.

11. Feldwieser FM, Sheeran L, Meana-Esteban A. Electromyographic analysis of trunk-muscle activity during stable, unstable and unilateral bridging exercises in healthy individuals. Eur Spine J. 2012;21(Suppl 2):S17186.

12. Marshall PW, Murphy BA. Core stability exercises on and off a Swiss ball. Arch Phys Med Rehabil. 2005;86(2):242-9.

13. Park YS. The effect of affected side trunk muscle activity in hemiplegia during asymmetrical bridging exercise with each different knee joint angles. Deagu Catholic University. Dissertation of Master's Degree. 2012.

14. Park MC. The effects of bridge exercise with different knee joint angles on stroke patients trunk muscle activity at different knee joint angle. Hallym University. Dissertation of Master's Degree. 2012.

15. Shim HB, Cho HY, Choi WH. Effects of the trunk stabilization exercise on muscle activity in lumbar region and balance in the patients with hemiplegia. J Kor Soc Phys Ther. 2014;26(1):33-40.

16. Jung KS, Chung YJ. Effects of the support surface condition on muscle activity of trunk muscles during weight shifting exercise. J Kor Soc Phys
Ther. 2012;24(5):300-5

17. Cram JR, Kasman GS, Holtz. Introduction to surface electro myography. Washington. Aspen publishers. 1993.

18. Bouisset S, Zattara M. Biomechanical study of the programming of anticipatory postural adjustments associated with voluntary movement. J Biomech. 1987;20(8):735-42.

19. Horak FB, Esselman P, Anderson ME et al. The effects of movement velocity, mass displaced, and task certainty on associated postural adjustments made by normal and hemiplegic individuals. J Neurol Neurosurg Psychiatry. 1987;47(9):1020-8.

20. Akuthota V, Nadler SF. Core strengthening. Arch Phys Med Rehabil. 2004;85(3 Suppl 1):S86-92.

21. Barr KP, Griggs M, Cadby T. Lumbar stabilization: Core concepts and current literature, Part 1. Am J Phys Med Rehabil. 2005;84(6):473-80.

22. Dean CM, Shepherd RB. Task-related training improves performance of seated reaching tasks after stroke. A randomized controlled trial. Stroke. 1997;28(4):722-8.

23. Carr LJ, Harrison LM, Stephens JA. Evidence for bilateral innervation of certain homologous motoneurone pools in man. J Physiol. 1994;475(2): 217-27.

24. Ferbert A, Caramia D, Priori A et al. Cortical projection to erector spinae muscles in man as assessed by focal transcranial magnetic stimulation. Electroencephalogr Clin Neurophysiol. 1992; 85(6):382-7.

25. Verheyden G, Vereeck L, Truijen S et al. Trunk performance after stroke and the relationship with balance, gait and functional ability. Clin rehab. 2006;20(5):451-8. 